\title{
An Investigation of Radiation Protection Status in Radiology Centers of Kurdistan in 2014-2015
}

\author{
Leila Ebrahimzadeh¹, Akbar Eslami², Farzam Bidarpoor ${ }^{3}$, Seyyed Jamal Aldin Ebrahimi ${ }^{*}$ \\ ${ }^{1}$ Department of Environmental Health Engineering, Kurdistan University of Medical Sciences, Sanandaj, Iran \\ ${ }^{2}$ Department of Environmental Health Engineering, Shahid Beheshti University of Medical Sciences, Tehran, Iran \\ ${ }^{3}$ Deputy of Health, Kurdistan University of Medical Sciences, Sanandaj, Iran \\ Email: ${ }^{*}$ brahimi.j89@gmail.com
}

How to cite this paper: Ebrahimzadeh, L., Eslami, A., Bidarpoor, F. and Ebrahimi, S.J.A. (2017) An Investigation of Radiation Protection Status in Radiology Centers of Kurdistan in 2014-2015. Health, 9, 849-856. https://doi.org/10.4236/health.2017.95060

Received: February 4, 2017

Accepted: May 20, 2017

Published: May 24, 2017

Copyright (c) 2017 by authors and Scientific Research Publishing Inc. This work is licensed under the Creative Commons Attribution International License (CC BY 4.0).

http://creativecommons.org/licenses/by/4.0/

\section{(c) (†) Open Access}

\begin{abstract}
Using personal protective equipment (PPE) properly and following available rules and regulations in the field of ionizing radiation protection can significantly decrease these harms. If these equipment and facilities are not available in diagnostic radiation centers or are not used properly, radiographers' and people's health will be jeopardized. To date, no study has examined the protective condition against radiation in diagnostic radiation centers of Kurdistan province. The present study, therefore, was an attempt to address this gap. This cross-sectional study was conducted in 2014-2015 among 35 diagnostic radiation centers of Kurdistan. Data were collected through a checklist (which was developed based on the available radiation protection laws), a survey for patients and their caregivers, and in-site observation and dosimetry. The radiation health expert of the province proceeded to each of the radiology centers personally. Upon arrival to each center, he informed health physics officials of the centers about the study and collected data through observation, interview, and the checklist. On the other hand, in order to examine radiation leakage in different modes of imaging session, dosimetry was conducted by the use of an environmental dosimeter (Fluke 451 manufactured in the United States). The collected data were analyzed through Excel. It was found that in $67.3 \%$ of the cases, there was personal protective equipment for patients and their caregivers (robes, thyroid strap, gonadal shield, glasses, and lead gloves). Furthermore, this equipment and other physical holders were used for patients and their caregivers in $75.7 \%$ of the cases. This rate was $87.6 \%$ for pregnant women. In addition, we found that around $94 \%$ of the personnel went through medical examinations every six or twelve months, a rate that was much higher than that found in Nohi's study. When it comes to improving the indices of protection against radiation in radiation centers, it seems that adding the proposed items in this study to the present data collection form (form 110 used for urban areas) or designing a new form will change the attitude toward
\end{abstract}


the concept of protection. This will highlight the importance of this topic and will result in decision makers' more serious attempts to promote the protection condition.

\section{Keywords}

Radiation Protection, Diagnostic Radiology Centers, Kurdistan

\section{Introduction}

Since its discovery, radiation has been used in medicine. Between 30 to 50 percent of medical decisions, especially the critical ones, are made after studying the results of radiological examinations [1] [2].

Even small degrees of radiation will certainly have the capability to harm body cells. In such cases, the damaged tissue will not be repaired [3]. When it comes to negative effects on human body, natural radiation is considered as a very important phenomenon. In contrast, most of the biological effects are caused by the ionizing radiation used in medicine [4].

Basically, it is logical to use a technological instrument only if its benefits outweigh its harms [5]. International Commission for Radiological Protection has introduced three principles that must be taken into account in diagnostic radiation centers: 1) justification of the radiation practice: no practice shall be adopted unless its introduction results in a positive net benefit; 2) optimization of the protection against radiation: all exposures shall be kept as low as reasonably achievable, economic and social factors being taken into account; 3 ) the degree of radiation: the doses to individuals shall not exceed the limits recommended for the appropriate circumstances by the Commission [6].

If individuals are exposed to a relatively high degree of radiation, they will certainly be influenced by its negative side effects. On the other hand, even small degrees of exposure to radiation can have possible side effects like cancer and genetic impacts on future generations. Thus, an effective way for reducing these harms is eliminating unnecessary radiations [7].

Using personal protective equipment (PPE) properly and following available rules and regulations in the field of ionizing radiation protection can significantly decrease these harms. If these equipment and facilities are not available in diagnostic radiation centers or are not used properly, radiographers' and people's health will be jeopardized [8].

International Commission for Radiological Protection has recommended that all exposures should be kept as low as reasonably achievable (ALARA), economic and social factors being taken into account [9].

Radiological tests should be conducted in a way that the required information is obtained with the lowest possible risk for the patient. Previous experience shows that physical parameters of active radioactive parameters do not enjoy a good exposure quality. This problem should be solved through a logical and reg- 
ular quality control plan. Otherwise, the risk of exposure to radiation goes up for people [10].

Radiographers should use film badge as a personal dosimeter. Other protective devices, such as thyroid shield, coat of lead, and lead glasses, should also be used especially in angiographic units [11]. Performing periodic medical examinations and controlling radiographers against the risk of radiation are two further measures that should be taken regularly under the supervision of health physics officials [12].

In addition, radiographers' health records should be controlled to gain information about conducted medical tests. By so doing, protective defects will be detected and steps can be taken to eliminate them. This will in turn improve protective conditions for radiographers [13].

According to National Council on Radiation Protection and Measurements (NCRP) in 2007, the maximum allowable average for non-radiation workers has been considered as 0.3 microsievert per hour [14]. In another report published in 2010, this value mounted to 0.12 microsievert per hour [15]. To date, no study has examined the protective condition against radiation in diagnostic radiation centers of Kurdistan province. The present study, therefore, was an attempt to address this gap.

\section{Materials and Methods}

This cross-sectional study was conducted in 2014-2015 among 35 diagnostic radiation centers of Kurdistan. Data were collected through a checklist (which was developed based on the available radiation protection laws), a survey for patients and their caregivers, and in-site observation and dosimetry.

The checklist included some items about radiation protection laws. These items encompassed the following areas: health physics officials' protective information, the procedure through which health physics officials exercised their supervision, the degree of following protective rules for radiographers, patients, and especially sensitive groups (e.g. creating the best condition for pregnant women), the standard degree of exposure for sensitive individuals, the time lapse between radiographers' protective examinations, the degree of personal dosimeter, the degree to which radiographers use personal dosimeters during radiation activities, the availability of personal lead shields and the degree of using them, the accessibility of physical holder for holding critically ill patients and kids and the degree of using patients' caregivers for holding patients, the amount of time in which each X-ray machine maker is used, the availability of digital imaging system, the type of processing system and the frequency of quality control tests on machines and darkrooms, the radiation leak of doors, windows, lead glasses, and windows used for transferring films to darkrooms, and the availability of optical, audio, and written alarms.

In addition, the surveys, which were distributed among health physics officials, contained questions related to the use of lead shields, caregivers' contribution to holding their patients (or using physical holders instead), pregnancy 
condition, age, gender, etc.

The radiation health expert of the province proceeded to each of the radiology centers personally. Upon arrival to each center, he informed health physics officials of the centers about the study and collected data through observation, interview, and the checklist. On the other hand, in order to examine radiation leakage in different modes of imaging session, dosimetry was conducted by the use of an environmental dosimeter (Fluke 451 manufactured in the United States). The collected data were analyzed through Excel.

\section{Findings}

As Figure 1 indicates, out of the 35 active diagnostic radiation centers in Kurdistan, 14 (40\%) had a valid license to work with X-ray, 10 (31.4\%) had the approval of the health department and were still trying to gain their license from Atomic Energy Organization, and the remaining 11 centers (28.6\%) did not have any license for working with X-ray. In terms of operating machines, 108 ones had the working license and 103 had a valid quality control certificate.

According to Figure 2, out of the entire number of 182 radiographers in the province, 47 (25.8\%) are interns and do not have any film badge in the first periods of radiography. This group is in a state of flux with old people leaving the internship program and new people joining it on a regular basis. Based on the same figure, 163 (89.17\%) radiographers use film badge. In terms of periodic medical examinations, 135 (74.3\%) radiographers go through it once every six months, 36 (19.6\%) undertake it once a year, and 11 (6.1\%) have no examination record.

Figure 3 indicates that, out of 108 medical-ray machines, $73(67.3 \%)$ have personal lead shields for patients and 35 (33.1\%) have personal lead shields for patients' caregivers. Out of these windshields, $51.3 \%$ of them are used for patients, $24.4 \%$ for caregivers, and $87.6 \%$ for pregnant women. Furthermore, 34 (31.2\%) machines have physical holders for kids and other patients, but only $11.8 \%$ of them were used.

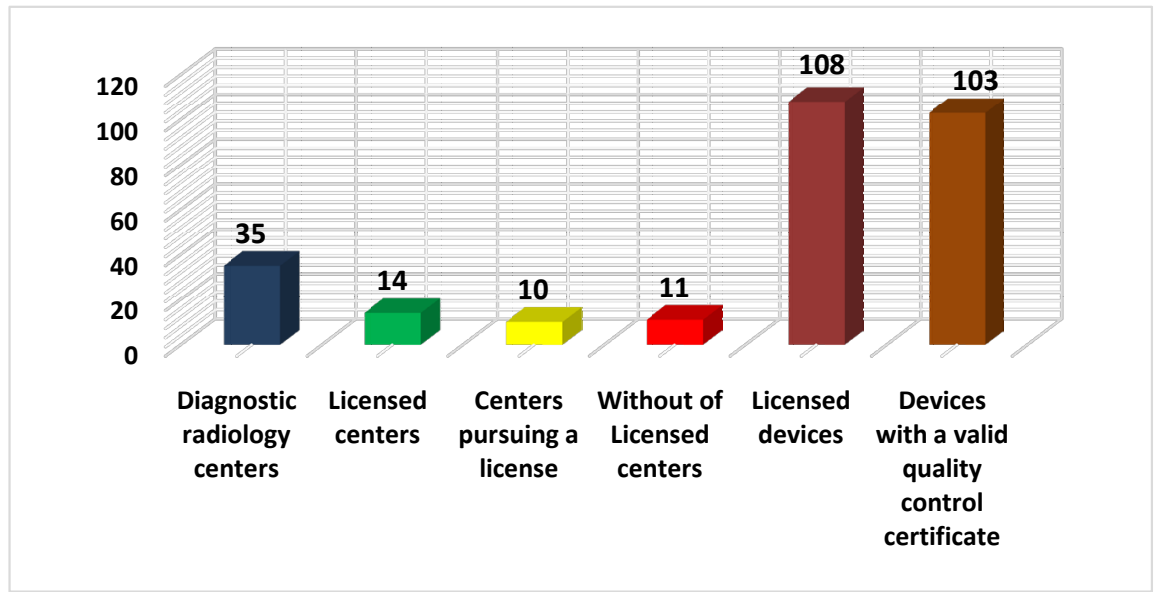

Figure 1. The existing state in terms of following radiation protection laws (license and quality control). 
Figure 4 illustrates that, out of 75 ray rooms, 55 (73.5\%) have warning lights, $50(66 \%)$ have audio alarms (horn), and 67 (88.8\%) have written warnings.

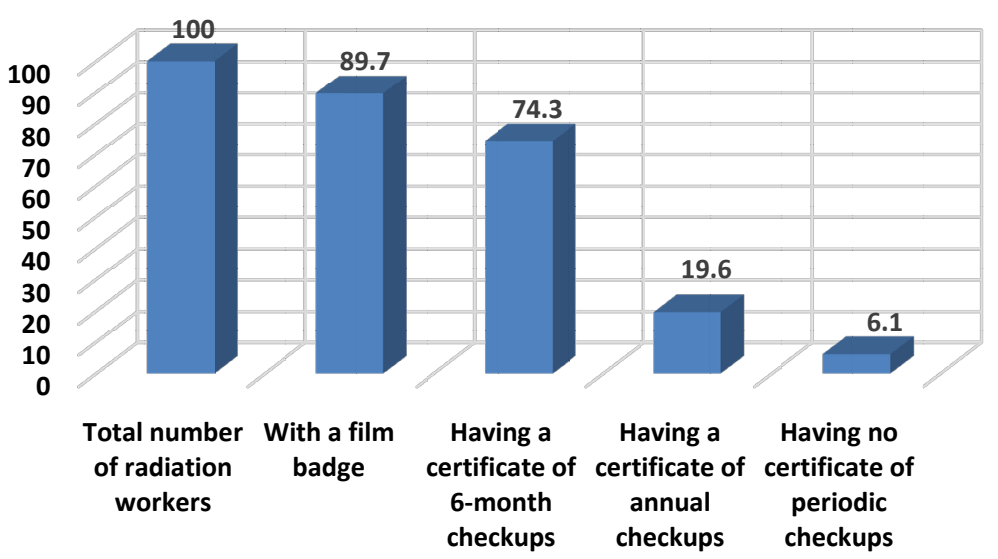

Figure 2. Radiographers' condition of protection and health.

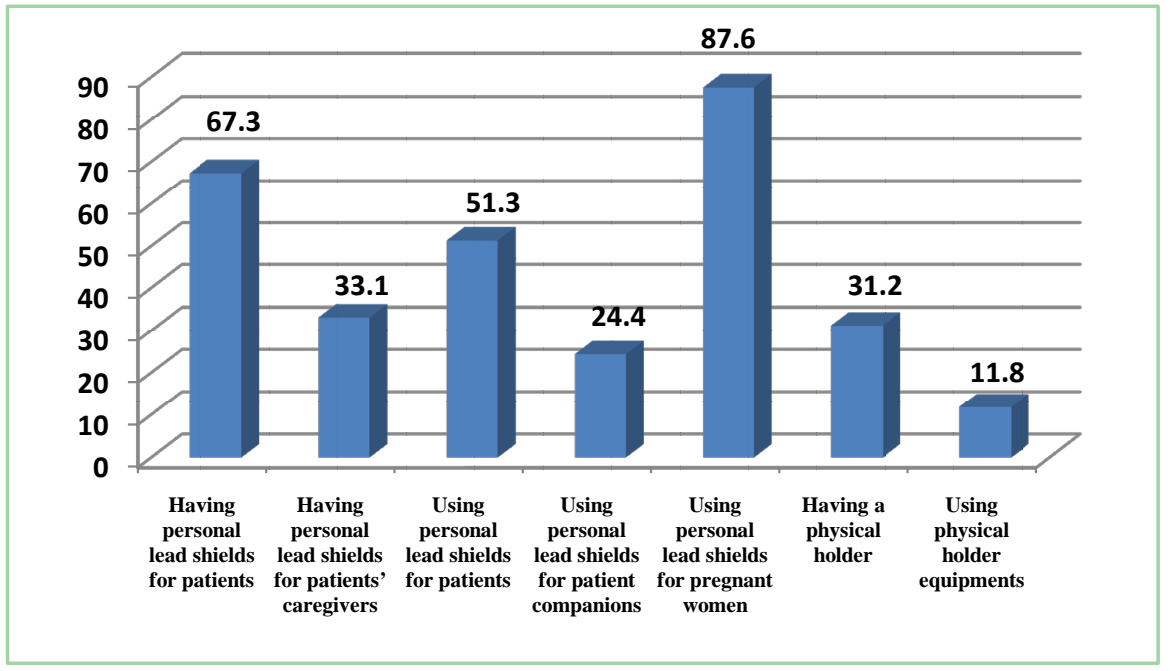

Figure 3. The degree of using personal lead shields.

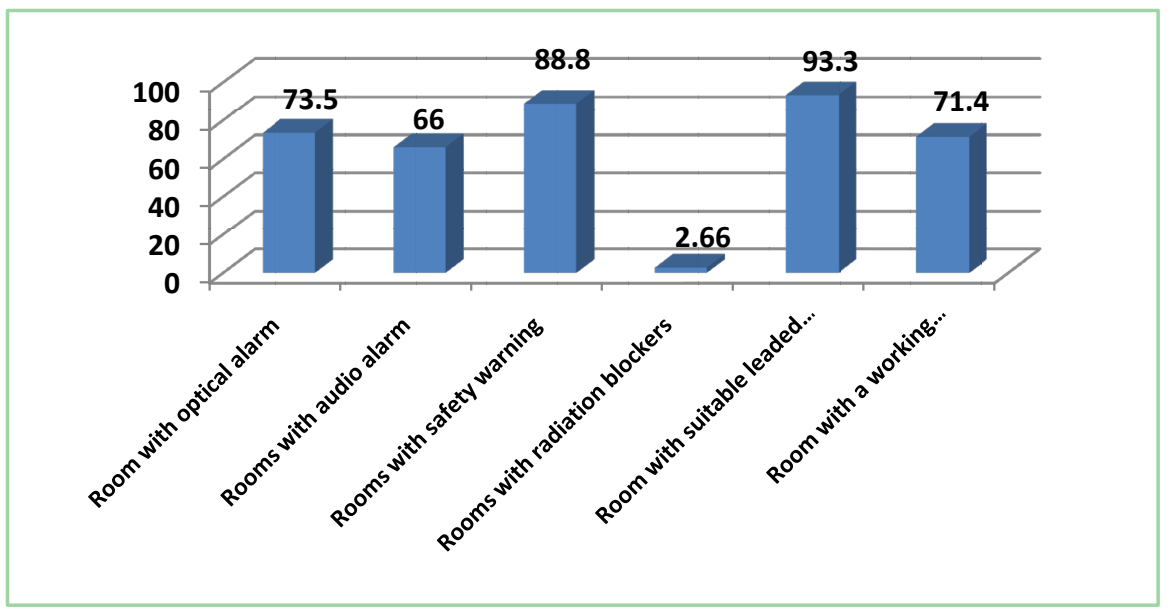

Figure 4. The state of warning signs. 
However, only $2(2.66 \%)$ rooms have a lock for cutting the ray. On the other hand, 70 (93.33\%) rooms have appropriate lead glasses and 54 (71.4\%) have working telecommunication devices.

According to Figure 5, 108 ray machines are used in 75 rooms. Among these rooms, leakage was observed in the lead glass of one $(1.33 \%)$ room, lead doors of $10(13.3 \%)$ control rooms, film transfer windows of 6 (8\%) radiology rooms, walls of $2(2.66 \%)$ ray rooms, bed-entrance doors of 26 (34.6\%) rooms. Some of the leakages were due to changes in radiation conditions. In 12 cases (16\%), doors, film transfer windows, and lead glasses were exposed to the primary radiation. Three other cases of radiation leakage were due to other factors such as improper coverage of lead over walls, improper or fake materials used in lead glasses, and the improper type of lead used.

\section{Discussion}

Nohi Bezanjani [16] demonstrated that $99 \%$ of diagnostic radiation centers of Kerman had the main personal protective equipment (e.g. individual bathrobes, thyroid strap, and gonad shield). Also, more than $82 \%$ of personnel were familiar with radiation protection laws, while $74 \%$ were familiar with personal protective equipment. On the other hand, only $15.7 \%$ of them used personal protective equipment, and they used this equipment for patients in only $1 \%$ of the cases. Around $50 \%$ of the personnel had attended at least one training period for becoming familiar with protection measures. Furthermore, $60 \%$ attended periodic medical examinations and over $88 \%$ had film badge. The researcher detected no significant relationship between individuals' awareness (of protective measures) and the use of personal protective equipment. The findings of that study are different from those of the current study. We found that in $67.3 \%$ of the cases, there was personal protective equipment for patients and their caregivers (robes, thyroid strap, gonadal shield, glasses, and lead gloves). Furthermore, this equipment and other physical holders were used for patients and their caregivers in $75.7 \%$ of the cases. This rate was $87.6 \%$ for pregnant women. In addition, we found that around $94 \%$ of the personnel went through medical examinations every six or twelve months, a rate that is much higher than that found in Nohi's study.

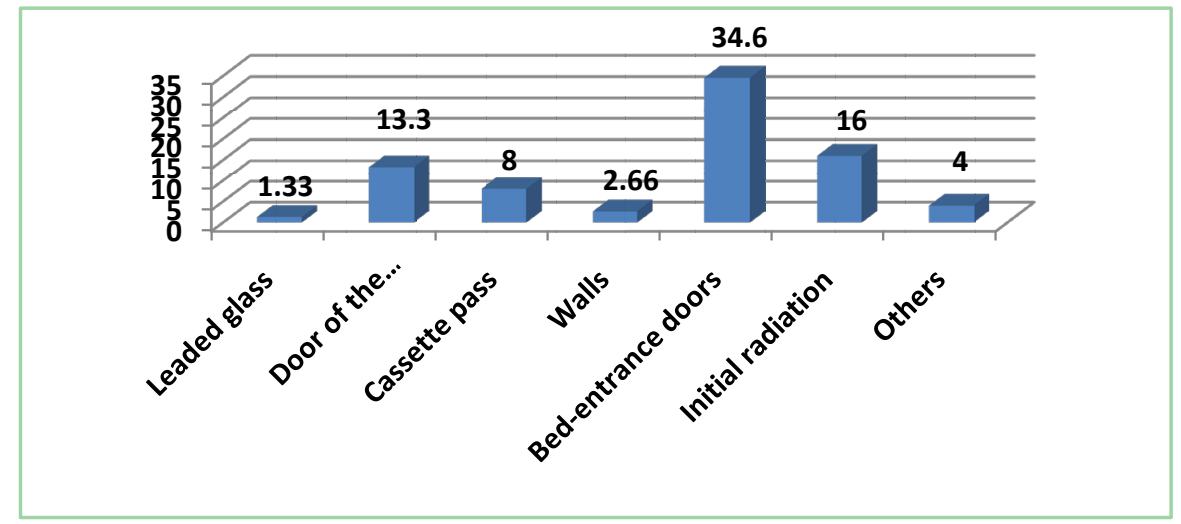

Figure 5. Dosimetry results for various parts of radiation centers. 


\section{Conclusions}

Ghazikhanlu and Eskandarlu [17] studied the condition for protection against radiation among all Faculties of Dentistry across the country. In terms of the availability of protective equipment (e.g. lead apron, thyroid shield, and dense lead walls) and the use of this equipment by radiographers, their findings were similar to ours.

However, Ghazikhanlu and Eskandarlu's study was different from the present one in terms of their findings with regard to the periodic quality control of the equipment. This was due to the fact that the quality of X-ray machines was acceptable in these faculties.

In another study, Tamjidi [18] investigated the state of protection against radiation in 25 radiological centers of Bushehr. They found that 22 centers had no protective gonad shield, 5 had no lead apron, and $30 \mathrm{X}$-ray rooms did not have any lead apron for caregivers. They also found that, in 10 centers, not all the personnel did use film badge, 22 rooms did not have any warning signal for no entry, and 21 rooms did not have any warning signal indicating the radiation area. Based on their findings, the protective condition in centers of Bushehr was not as good as that in our study. Furthermore, the degree of using personal lead shields was much higher in Kurdistan compared to Bushehr.

When it comes to improving the indices of protection against radiation in radiation centers, it seems that adding the proposed items in this study to the present data collection form (form 110 used for urban areas) or designing a new form will change the attitude toward the concept of protection. This will highlight the importance of this topic and will result in decision makers' more serious attempts to promote the protection condition.

\section{Limitation}

The main limitation of this study concerned with the lack of past research studies on the same topics which could be helpful in the current paper.

\section{References}

[1] Arslanoglu, A., Bilgin, S., Kubal, Z., Ceyhan, M.N., Ilhan, M.N. and Maral, I. (2007) Doctors' and Intern Doctors' Knowledge about Patients' Ionizing Radiation Exposure Doses during Common Radiological Examinations. Diagnostic and Interventional Radiology, 13, 53-55.

[2] European Commission (2004) European Guidelines on Radiation Protection in Dental Radiology. The Safe Use of Radiographs in Dental Practice. Issue N 136.

[3] Gopal, A.K., Whitehouse, J.D., Simel, D.L. and Corey, G.R. (1999) Cranial Computed Tomography before Lumbar Puncture: A Prospective Clinical Evaluation. Archives of Internal Medicine, 159, 2681-2685. https://doi.org/10.1001/archinte.159.22.2681

[4] Hall, E.J. and Giaccia, A. (2011) Radiobiology for the Radiologist. 7th Edition, Lippincott Williams \& Wilkins, Philadelphia, 455-466.

[5] Tahmasbpour, H.R. (1991) Principles of Clinical Radiology. Chapavol, 8-22.

[6] Ghiasinezhad, M. and Katuzi, M., Eds. (1994) General Courses on Protection 
against Radiation. Special Education Preparatory Courses. Chapavol, Tehran, Darbid Company.

[7] Rahimi, S. and Salar, S. (2005) A Study on the Performance of Recommended Standards in the Diagnostic Radiology Units of the Hospitals Affiliated to the Mazandaran University of Medical Sciences. Journal of Mazandaran University of Medical Sciences, 15, 69-76. (Article in Persian)

[8] Holm, L.E. (2007) ICRP's 2007 Recommendations on Radiological Protection. International Commission on Radiological Protection, EU Conference, Berlin, Germany, 19 June 2007.

[9] International Commission on Radiological Protection (1990) 1990 Recommendations of the International Commission on Radiological Protection. Annals of the ICRP, 21, 1-3.

[10] Declan, R., Kyrio, J., Edward, J. and Andrew, C.M.F. (2001) Radiation Protection in Interventional Radiology. Clinical Radiology, 56, 99-106. https://doi.org/10.1053/crad.2000.0640

[11] IAEA (2005) International Basic Safety Standards for Protection against Ionizing Radiation and for the Safety of Radiation Sources. S.S No. 115.

[12] Rodier, J. and Chassany, J.P. (2007) Manual de Radio Protection. S. A. Malonie, Editor.

[13] Tavakoli, M.B. (2004) Radiobiology and Protection against Radiation.2nd Edition, Mania Publications, Isfahan, 5-45.

[14] Shahabi, N., GhorbaniShahna, F., Roknian, M., Goodarzi, S. and Samavat, H. (2004) The Survey Measure Confront of Radiation Workers in Instructural Hospitals and Departments of Dental Clinics in Hamadancity, 2002. 4th Symposium of Professional Health Fields, Hamadan, 695-703. (In Persian)

[15] Salem, D. and Mamdouh Abdel-Rahman, M. (2011) Standard Specifications for Basic Diagnostic Radiology Departments, Quality Radiology Services for Better Health. Egypt-Swiss Radiology Project (ESRP), 1-47.

[16] Nohi Bezanjani, J. (2009) Investigating the Degree to Which Personal Protection Laws Are Observed for Radiographers and Patients in Diagnostic Radiation Centers of Kerman. The 12 th National Conference of Environmental Health in Iran, Shahid Beheshti University of Medical Sciences, School of Public Health, Tehran, Iran, October 2009.

[17] Ghazikhanlu, K. and Eskandarlu, A. (2009) Investigating the Degree to Which Personal Protection Laws Are Observed in Faculties of Dentistry across the Country. Dentistry Journal of Tehran University of Medical Sciences and Health Services, 22.

[18] Tamjidi, A. (2005) The Condition for Observing the Radiation Protective Principles in Radiological Centers of Bushehr. South Medicine, 4. 
Submit or recommend next manuscript to SCIRP and we will provide best service for you:

Accepting pre-submission inquiries through Email, Facebook, LinkedIn, Twitter, etc. A wide selection of journals (inclusive of 9 subjects, more than 200 journals)

Providing 24-hour high-quality service

User-friendly online submission system

Fair and swift peer-review system

Efficient typesetting and proofreading procedure

Display of the result of downloads and visits, as well as the number of cited articles Maximum dissemination of your research work

Submit your manuscript at: http://papersubmission.scirp.org/

Or contact health@scirp.org 